\title{
Microscope assisted coblation tonsillectomy: a safe and effective surgical technique
}

\author{
Santosh Kumar Swain ${ }^{1 *}$, Alok Das ${ }^{1}$, Bulu Nahak ${ }^{1}$, Ishwar Chandra Behera ${ }^{2}$
}

\author{
${ }^{1}$ Department of Otorhinolaryngology, ${ }^{2}$ Department of Community Medicine, IMS and SUM Hospital, Siksha O \\ Anusandhan University (Deemed to be), Bhubaneswar, Odisha, India
}

Received: 01 April 2019

Accepted: 26 June 2019

\section{*Correspondence:}

Dr. Santosh Kumar Swain,

E-mail: santoshvoltaire@yahoo.co.in

Copyright: () the author(s), publisher and licensee Medip Academy. This is an open-access article distributed under the terms of the Creative Commons Attribution Non-Commercial License, which permits unrestricted non-commercial use, distribution, and reproduction in any medium, provided the original work is properly cited.

\begin{abstract}
Coblation is a new technology used in soft tissue surgery. This technique uses lower energies than standard bipolar diathermy. It does ablation at lower temperature which causes less damage to the surrounding tissues and also less post-operative pain. Microscope assisted tonsillectomy is a new surgical technique and established as a suitable and standard method of tonsillectomy. Microscope-assisted coblation tonsillectomy reduces the intra-operative and postoperative hemorrhage, post-operative pain and decrease the hospital stay, so that help in an early improvement of the patient. This technique is associated with less pain and quick return to normal diet and daily activity of the patient. This technique is an effective and safe technique for doing tonsillectomy. Surgeons can also operate with precision in enlarged and magnified view in microscope or endoscope assisted tonsillectomy. Moreover, this technique makes it easier to educate the students. The purpose of this review article is to discuss the principle, techniques, outcome, advantages and limitations of microscope assisted coblation tonsillectomy.
\end{abstract}

Keywords: Tonsillectomy, Coblation, Microscope assisted, Post-operative pain, Secondary hemorrhage

\section{INTRODUCTION}

Palatine tonsils are lymphoid tissues located at the oropharynx within the tonsillar fossa. In pediatric age palatine tonsils has role in defense mechanism and immunology. Secretion of antibody like IgA plays an important role in the mucosal defense mechanism. In case of repeated infections of tonsils, the protective mechanisms of tonsils fail and cause sore throat, fever and other complications for which it need tonsillectomy. ${ }^{1}$ Tonsillectomy is a common surgical procedure in otolaryngological practice. Tonsillectomy is a surgical procedure where post-operative pain, hemorrhage and other complications are seen. There are different surgical technique for tonsillectomy have been successfully attempted since long back like guillotine method, diathermy, dissection method to more recent method like laser, ultrasonic and coblation. The postoperative complications like pain in throat, hemorrhage, otalgia and fever. ${ }^{2}$ Coblation is an advanced technology used for tonsillectomy in present days. This technology combines gentle radiofrequency energy with a natural salt solution too quickly. Coblation never removes tissue by heating or burning. ${ }^{3}$ The primary advantage of microscope assisted coblation tonsillectomy is the ability to observe the detailed anatomy of the extra-capsular loose tissues in the tonsillar bed. In addition to magnified view of the surgical field, the surgical assistants and students can directly see the surgical steps by external monitor or secondary mirror. Microscope assisted tonsillectomy could be an effective tool for educating students and young surgeons and to minimize the complications. This review article is aimed to discuss the intra-operative hemorrhage, surgical duration, postoperative pain, reactionary hemorrhage, secondary hemorrhage and hospital stay after surgery in patients undergoing microscope assisted coblation tonsillectomy. 


\section{METHODS OF LITERATURE SEARCH}

Research articles regarding coblation tonsillectomy under assistance of microscope were searched through a multisystemic approach. First we conducted an online search of the PubMed, Scopus and Medline database with the word tonsillectomy, coblation, microscope assisted in compared to conventional coblation tonsillectomy.

\section{HISTORY OF COBLATION TONSILLECTOMY}

Tonsillectomy is a common surgical procedure which was first performed 3000 years ago. $^{4}$ Initially cold instruments are often used to minimize the heat induced damage to the tissue by conventional tonsillectomy through dissection. There are several newer technologies like lasers, harmonic scalpels, microdebrider and coblation tonsillectomy. ${ }^{5}$ Coblation tonsillectomy was first introduced in 2001 as a surgical tool after which a number of research articles have been published either to confirm its efficacy ${ }^{7}$ or to reject as of unsatisfactory or not suitable with cost-effectiveness. ${ }^{8}$ There are very few research articles in microscope or endoscope assisted tonsillectomy. Although coblation is popularly used by Otolaryngologists in China, but it is now a common surgical tool for performing tonsillectomy worldwide. ${ }^{9}$

\section{TECHNIQUES USED FOR TONSILLECTOMY}

Tonsillectomy is one of the common surgical procedures performed by Otolaryngologists during their practice period. Despite different range of techniques for tonsillectomy including guillotine, blunt dissection, diathermy or laser and the use of several analgesics, postoperative pain and hemorrhage are the major side effects of this operation. ${ }^{10}$ In addition to above techniques, there are several newer methods like CO2 lasers, harmonic scalpel using ultrasonic energy, micro-debriders and coblation using bipolar radiofrequency ablation. ${ }^{11}$ Very few surgeons perform tonsillectomy under microscope vision. ${ }^{12}$ Tonsillectomy often regarded as simple surgery and surgeons often are not bothered for further optimization and development in this field. Use of the coblation technique in tonsillectomy has added several advantages in comparison to alternative form of surgery. Coblation tonsillectomy has the important advantage by giving limited thermal injury in comparison to other techniques used for tonsillectomy. The term coblation is derived from the word "controlled ablation" which means non-heat driven process for soft tissue dissociation by use of bipolar radiofrequency energy to excite electrolytes in conductive medium as in saline solution. ${ }^{13}$

\section{PRINCIPLE OF COBLATION TONSILLECTOMY}

Coblation technique uses bipolar radiofrequency energy which generate a field of ionized sodium molecules which ablates and coagulates soft tissue without any thermal injury. Conductive saline solution kept in the gap between the device tip and the soft tissue and converted into an ionized plasma layer. When this plasma layer touches with tissue, there is enough energy to break the molecular bonds, leading to molecular dissociation. This effect is resulted at temperatures of about $40^{\circ} \mathrm{C}$ to $70^{\circ} \mathrm{C}$ so reducing thermal damage to the tissues. ${ }^{14}$

\section{POST-OPERATIVE PAIN}

Coblation is a promising technology for tonsillectomy. Major advantage following tonsillectomy is reduced postoperative pain. ${ }^{15}$ Post-operative pain is an important factor which limits the recover from the surgical procedure. Inadequate pain relief can delay and prevent hospital discharge. ${ }^{16}$ Telephonic follow up for postoperative pain is usually done on the $4^{\text {th }}, 7^{\text {th }}$ and $15^{\text {th }}$ day as it often coincides with the key stages in the evolution of the post-tonsillectomy inflammatory process. The maximum inflammation of the tonsillectomy wound produced in the $3^{\text {rd }}$ and 5th days of the post-operative period whereas the separation of the fibrin clot formed around the $7^{\text {th }}$ day after the surgery. ${ }^{17}$ Similarly the appearance of the hemorrhagic process at the $14^{\text {th }}$ days of the post-operative period in some cases made the patient follow up during $2^{\text {nd }}$ week appropriately. Patients start eating with very little discomfort following surgery. A more comprehensive study is required on the postoperative pain after coblation which will show more light on this technology. Coblation is a popular technique for performing tonsillectomy as it purportedly causes less post-operative pain than any other surgical methods. However, the superiority of coblation is unproven.

\section{INTRA-OPERATIVE AND POST-OPERATIVE HEMORRHAGE}

Coblation technique for tonsillectomy result in lower intra-operative blood loss which is helpful in pediatric age group, particularly in those with bleeding disorders, anemia and children with less than 3 years old. ${ }^{18}$ During intra-operative time, the ablation mode with a plasma wand is performed only for loose soft tissue between pharyngeal muscles and capsule of the tonsil so that it will avoid direct damage to the pharyngeal muscles during microscope assisted coblation tonsillectomy. In comparison to coblation tonsillectomy without assistance of microscope, the capsule of the tonsils can be easily distinguished along with fine blood vessels over it. The nourishing blood vessels entering the tonsils are only occluded during this surgery. Injury to the paratonsillar veins and tonsillar arteries are effectively avoided by use of the operating microscope. In our cases, injury to the paratonsillar vein (external palatine vein) is an important and major cause for bleeding during surgery by conventional method. Taking the help of operating microscope help to distinguish and occlude these veins over the capsule of the tonsils, so easily limit the blood loss. Microscope assisted coblation tonsillectomy is an improvement over all techniques used for tonsillectomy since past with respect to damage to the soft tissue at the surgical field including blood vessels. ${ }^{19}$ 


\section{OUTCOME OF THE COBLATION TONSIL- LECTOMY}

The outcome of the technique utilized for tonsillectomy is based on the duration of the surgery, intra-operative blood loss and postoperative pain. Intra-operative blood loss is often calculated by a nurse on the basis of fluid drained via the suction minus the volume of saline flush. The postoperative hemorrhage is defined as continuous bleeding that a patient has to spit out of the mouth or swallow. Primary hemorrhage occurs during the surgery whereas reactionary hemorrhage occurs within 24 hours after the surgery whereas secondary hemorrhage occurs after 24 hours postoperatively. Tonsillectomy often needs 2 to 4 days hospitalization and observation. The special hospital staffs are instructed to do postoperative telephonic follow up where the doctors guide the patients for taking oral analgesics. The telephonic enquiry detects pain scores for first postoperative days.

\section{ADVANTAGES OF COBLATION TONSIL- LECTOMY}

Coblation technology functions at a significantly lower temperature than conventional method like diathermy. The surrounding tissues are also exposed to less heat in coblation. One study on rats compared tongue incision by coblation system (ArthoCare) with a conventional bipolar electrosurgery. ${ }^{20,21}$ This study revealed that coblation dissection has a advantages over conventional bipolar dissection in terms of minimal tissue damage and faster healing. The cost of the coblation machine may be reasonable but the cost of the wand may be a major burden for performing tonsillectomies. But with recent infection control problems in doing tonsillectomy, this financial part may be less a problem as we make a change to disposable tonsillectomy instruments in the light of the perceived link between tonsillar tissue and newer variant of Creutzfeldt Jacob disease. There several studies support the less postoperative pain levels, early healing of the wound and early return to a normal diet in coblation in comparison to bipolar dissection tonsillectomy. ${ }^{22}$ The duration of the surgery in case of endoscopic assisted tonsillectomy is shorter compared to the conventional technique as setup time for the procedure is a few minutes. ${ }^{23}$ The enlarged and clear view of the operative field is available in microscopic or endoscopic assisted tonsillectomy which help surgeon to operate with precision particularly when dealing with tonsil capsules or small vessels entering the tonsils.

\section{COBLATION VERSUS ELECTROCAUTERY TONSILLECTOMY}

Coblation (radiofrequency ablation) is relatively newer technique for tonsillectomy which utilizes bipolar radiofrequency to make current through saline medium. When saline particles are ionized, this energy is transferred to molecular bonds which make up tissue, leading in ablation. The advantages of coblation over electrocautery lies in the temperature reduction which allows tissue ablation to be achieved at temperature between $40^{\circ} \mathrm{C}$ to $70^{\circ} \mathrm{C}$ whereas in electrocautery, the temperature reaches to more than $400{ }^{\circ} \mathrm{C} .^{24}$ The lower temperature of the coblation causes less heat dissipation into the surrounding tissue, so make reduced postoperative pain. $^{25}$

\section{BENEFITS OF MICROSCOPE COBLATION TONSILLECTOMY \\ ASSISTED}

The important advantages of tonsillectomy under operating microscope (Figure 1) over direct vision are ability to visualize the detailed anatomy of the extracapsular loose soft tissues of the tonsil. In addition to good visualization, students and trainees can directly see the surgical steps through monitor or observer eye piece. Although many surgeons have microscope, majority do tonsillectomies under direct vision. Many surgeons do tonsillectomies under head lamp or surgical loupe although the lighting and magnifications of the surgical field are inferior to those seen under a operating microscope. In comparison to head light and loupe, the magnification of the operating microscope can be adjusted any point during surgery. The microscope is adjusted to $3 \mathrm{X}$ at the initial part of the surgery and it can be increased to $6-8 \mathrm{X}$ for precise separation of the tonsil from the tonsillar bed and blood vessels. The visualization and axis of the light are usually parallel; provide deep illumination and visualization of the operating or surgical site (Figure 2). Moreover, the operative microscope prevents the field of view from the moving as it has a mechanical arm bracket. These features of the operative microscope enhance the visualization of the tonsillar bed. Operative microscope provides better quality of brightness, color and clarity of the light than head light and loupes. It can also be connected to an image display system for providing better quality of teaching to the trainees. Use of the operating microscope allows not only better visualization of the surgical field but also lower pole of the tonsils, so there will be no residual lower pole tissue and cause again infection and hypertrophy in future. ${ }^{26}$ Use of the operating microscope provide better representation of the brightness, colour and clarity of the operative field than head light or loupes and which can be connected to the image display system for facilitating the teaching to students. ${ }^{27}$ The visual field in tonsillectomy under head light is narrow, so it is difficult for others to view the surgical field except the surgeon. This makes a difficult situation for training the students or resident surgeons and to show the progression of the tonsillectomy. Microscopic assisted tonsillectomy is very effective for educating the students, resident surgeons or beginning surgeons in tonsillectomy procedure. It will help to show the enlarged view of the narrow oral and oropharyngeal area. Moreover, anesthetists or nurses can confirm the progression of the surgery by seeing it through the monitor. This technique can be used in case of oropharyngeal carcinomas or other benign lesions. 


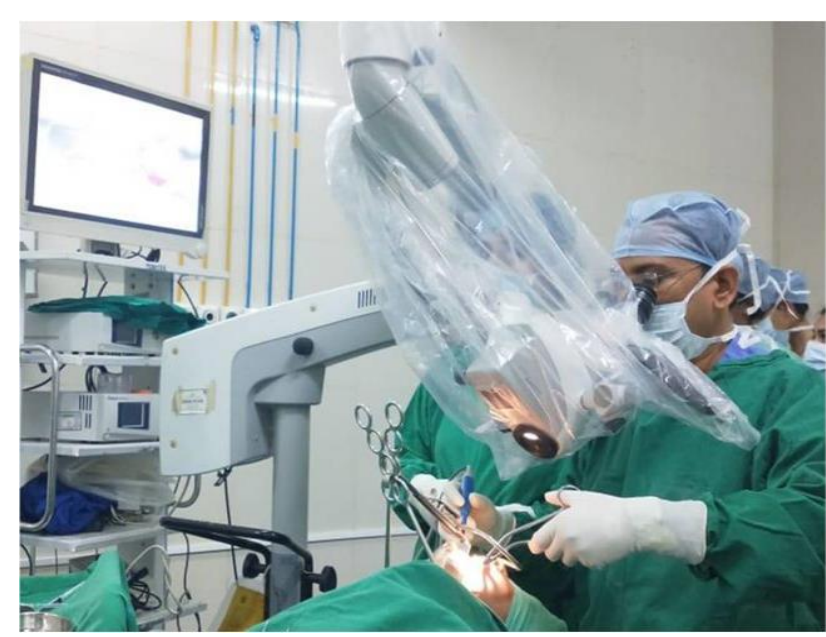

Figure 1: Position of the patient during microscope assisted coblation tonsillectomy.

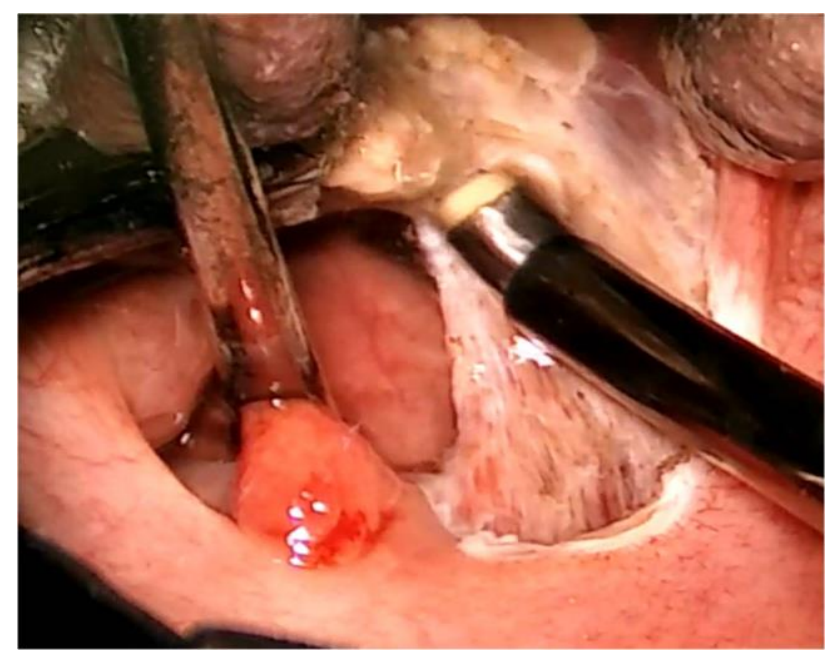

Figure 2: Intra-operative view of the microscope assisted coblation tonsillectomy.

\section{LIMITATIONS OF COBLATION TONSIL- LECTOMY}

Most important disadvantages with this plasma device are often require learning curve, although it relatively shorter period. The expense of the wand is another disadvantage where a wand is needed for each patient. The total instruments used for coblation is more costly than instruments for cold tonsillectomy. Care should be given to avoid any injury to the face and lips as these areas are not included in this view.

\section{CONCLUSION}

Microscope assisted coblation tonsillectomy allows minimal invasive intervention, reduced intra-operative blood loss, short duration of surgery, less postoperative pain, reduced hospital stay and less chance of reactionary and secondary hemorrhage in comparison to conventional tonsillectomy. The use of operating microscope does not simply enhance the field of vision, but also offers an innovative change to the surgical approach.

Funding: No funding sources

Conflict of interest: None declared

Ethical approval: Not required

\section{REFERENCES}

1. Sasindran V, Mathew N, Shabna AK, Harikrishan B. Comparison of Coblation Tonsil-lectomy vs Dissection Tonsillectomy. Int J Otolaryngol Head Neck Surg. 2019;8:49-60.

2. Meybodian M, Dadgarnia M, Baradaranfar M, Vaziribozorg S, Mansourimanesh M, Mandegari M, et al. Effect of cold diet and diet at room temperature on post-tonsillectomy pain in children. Iranian J Otolaryngol. 2019;25:81-6.

3. Lin C, Thung AK, Jatana KR, Cooper JN,Barron LC, Elmaraghy CA. Impact of coblation versus electrocautery on acute post-operative outcomes in pediatric tonsillectomy. Laryngoscope Investigative Otolaryngol. 2019;4(1):154-9.

4. McNeill RA. A history of tonsillectomy:two millenia of trauma, haemorrhage and controversy. Ulster Med J. 1960;29:59-63.

5. Wilson YL, Merer DM, Moscatello AL. Comparison of three common tonsillectomy techniques:a prospective randomized, doubleblinded clinical study. Laryngoscope. 2009;119:162-70.

6. Anderson SR, Faucett SC, Flanigan DC, Gmabardella RA, Amin NH. The history of radiofrequency energy and Coblation in arthroscopy:a current concepts review of its application in chondroplasty of the knee. J Experimental Orthop. 2019;6(1):1

7. Polites N, Joniau S, Wabnitz D, Fassina R, Smythe $\mathrm{C}$, Varley $\mathrm{P}$, et al. Postoperative pain following coblation tonsillectomy:randomized clinical trial. ANZ J Surg. 2006;76(4):226-9.

8. Burton MJ, Dorce C. Coblation versus other surgical techniques for tonsillectomy. Cochrane Database Syst Rev. 2007;3:CD004619.

9. Rakesh S, Anand TS, Payal G, Pranjal K. A Prospective, randomized, double-blind study of coblation versus dissection tonsillectomy in adult patients. Indian J Otolaryngol Head Neck Surg. 2012;64:290-4.

10. Ragab AA, Manzlgi MA, Fakoury MM. Rate of post-tonsillectomy haemorrhage in different tonsillectomy techniques:Retrospective study, Dubai hospital experience in 16-Month period. Hamdan Med J. 2018;11(2):70.

11. Noordzij JP, Affleck BD. Coblation versus unipolar electrocautery tonsillectomy: a prospective, randomized, single-blind study in adult patients. Laryngoscope. 2006;116:1303-9.

12. Belloso A, Chidambaram A, Morar P, Timms MS. Coblation tonsillectomy versus dissection 
tonsillectomy: postoperative hemorrhage. Laryngoscope. 2003;113:2010-3.

13. Leong AT, Ganhasan S, Sun PL, Wai YH, Yuan IL, Poh HP, Huak CY. PEAK plasma blade versus monopolar electrocautery tonsillectomy in adults:A prospective double blinded randomized controlled trial. Am J Otolaryngol. 2019;40(4):478-81.

14. Temple RH, Timms MS. Paediatric coblation tonsillectomy. Int $\mathbf{J}$ Pediatr Otorhinolaryngol. 2001;61:195-8.

15. Parsons SP, Cordes SR, Comer B. Comparison of posttonsillectomy pain using the ultrasonic scalpel, coblator, and electrocautery. Otolaryngol Head Neck Surg. 2006;134(1):106-13.

16. Thung AK, Elmaraghy CA, Barry ND, Tumin D, Jatana KR, Rice J, et al. Double blind randomized placebo controlled trial of single dose intravenous acetaminophen for pain associated with adenotonsillectomy in pediatric patients with sleep disordered breathing. J Pediatr Pharmacol Therap. 2017;22(5):344-51.

17. Isaacson G. Tonsillectomy healing. Ann Otol Rhinol Laryngol. 2012;121:645-9.

18. Kwok MM, Subramaniyan M, Rimmer J, Karahalios A. Post-tonsillectomy haemorrhage in Australia - a multivariable analysis of risk factors. Australian J Otolaryngol. 2018;1(1).

19. Magdy EA, Elwany S, el-Daly AS, Abdel-Hadi M, Morshedy MA. Coblation tonsillectomy:a prospective, double-blind, randomised, clinical and histopathological comparison with dissectionligation, monopolar electrocautery and laser tonsillectomies. J Laryngol Otol. 2008;122:282-90.

20. Chinpairoj S, Feldman MD, Saunders J, Thaler E. A comparison of monopolar electrosurgery to a new multipolar electrosurgical system in a rat model. Laryngoscope. 2001;111:213-7.
21. Coblator Plasma Surgery System, ENTec, ArthroCare Corporation, 595 North Pastoria Avenue, Sunnyvale, CA: 94086.

22. Roje Z, Racić G, Dogas Z, Pisac VP, Timms M. Postoperative Morbidity and Histopathologic Characteristics of Tonsillar Tissue Following Coblation Tonsillectomy in Children: A Prospective Randomized Single-Blind Study. Coll Antropol. 2009;33:1:293-8.

23. Nakaya M, Kimura Y, Onuki Y, Kida W, Shiraishi A, Fujimoto C, et al. Endoscopic-Assisted Tonsillectomy. Laryngoscope. 2013;123:360-1.

24. Friedman M, LoSavio P, Ibrahim H, Ramakrishnan V. Radiofrequency tonsil reduction: safety, morbidity, and efficacy. Laryngoscope. 2003;113(5):882-7.

25. Rinaldi V, Costantino A, Moffa A, Cassano M, Mantovani M, Casale M, et al. Postoperative Pain and Wound Healing After Coblation-Assisted Barbed Anterior Pharyngoplasty (CABAPh):An Observational Study. Indian J Otolaryngol Head Neck Surg. 2019: 1-6.

26. Pang Y, Gong J, Huang J, He S and Zhou H. Coblation tonsillectomy under surgical microscopy: A retrospective study. J Int Med Res. 2016;44(4):923-30.

27. Yi Wong DJ, Paddle P. Harmonic scalpel versus other techniques for tonsillectomy: a systematic review and meta-analysis. Australian J Otolaryngol. $2019 ; 2$.

Cite this article as: Swain SK, Das A, Nahak B, Behera IC. Microscope assisted coblation tonsillectomy: a safe and effective surgical technique. Int J Otorhinolaryngol Head Neck Surg 2019;5:1446-50. 